\title{
Erratum to: Global guidance on environmental life cycle impact assessment indicators: findings of the scoping phase
}

\author{
Olivier Jolliet • Rolf Frischknecht • Jane Bare • Anne-Marie Boulay • Cecile Bulle • Peter Fantke • \\ Shabbir Gheewala • Michael Hauschild • Norihiro Itsubo • Manuele Margni - Thomas E. McKone • \\ Llorenç Mila y Canals • Leo Posthuma • Valentina Prado-Lopez • Brad Ridoutt • Guido Sonnemann • \\ Ralph K. Rosenbaum • Tom Seager • Jaap Struijs • Rosalie van Zelm • Bruce Vigon • \\ Annie Weisbrod • with contributions of the other workshop participants
}

Published online: 17 June 2014

(C) Springer-Verlag Berlin Heidelberg 2014

Erratum to: Int J Life Cycle Assess

DOI 10.1007/s11367-014-0703-8

Unfortunately, the name of the thirteenth author was misspelled. The correct spelling is Leo Posthuma.

The online version of the original article can be found at http://dx.doi.org/ 10.1007/s11367-014-0703-8.

O. Jolliet $(\bowtie)$

School of Public Health, Environmental Health Sciences, University of Michigan, Ann Arbor, MI 48109, USA

e-mail: ojolliet@umich.edu

R. Frischknecht

treeze Ltd., Uster, Switzerland

J. Bare

National Risk Management Research Laboratory, Sustainable Technology Division, Systems Analysis Branch, United States

Environmental Protection Agency, Cincinnati, OH, USA

A.-M. Boulay $\cdot$ C. Bulle $\cdot$ M. Margni

CIRAIG, Ecole Polytechnique de Montreal, Montreal, Canada

P. Fantke $\cdot$ M. Hauschild $\cdot$ R. K. Rosenbaum

Department of Management Engineering, Technical University

Denmark, Kgs. Lyngby, Denmark

S. Gheewala

The Joint Graduate School of Energy and Environment, King Mongkut's University of Technology, Thonburi, Thailand

N. Itsubo

Tokyo City University, Yokohama, Japan

T. E. McKone

School of Public Health, University of California, Berkeley, CA, USA

L. M. y Canals

Safety and Environmental Assurance Centre, Unilever, Sharnbrook, UK
L. M. y Canals

Division of Technology, Industry and Economics, United Nations Environment Programme, Paris, France

L. Posthuma $\cdot$ J. Struijs

National Institute of Public Health and the Environment (RIVM), Bilthoven, The Netherlands

V. Prado-Lopez $\cdot$ T. Seager

School of Sustainable Engineering and the Built Environment, Arizona State University, Tempe, AZ, USA

B. Ridoutt

Sustainable Agriculture National Research Flagship, Commonwealth Scientific and Industrial Research Organisation (CSIRO), Clayton South, VIC, Australia

G. Sonnemann

Univ. Bordeaux, ISM, UMR 5255, Bordeaux, France

R. van Zelm

Department of Environmental Science, Radboud University Nijmegen, Nijmegen, The Netherlands

B. Vigon

SETAC, Pensacola, FL, USA

A. Weisbrod

Procter \& Gamble, Cincinnati, OH, USA 